\title{
Kronik Periodontitis ile Agresif Periodontitisin Farklılıkları
}

\author{
Differences Between Chronic and Aggressive Periodontitis
}

Hatice Selin YILDIRIM @, Nimet Gül GÖRGÜLÜ @D, Kübra KUNDAK @ , Leyla KURU

\section{GíRiş}

Günümüzde "kronik periodontitis" olarak isimlendirilen periodontal hastalığın sebebinin, 1800 'lerin sonlarında diş yüzeyindeki kireç birikimi olduğu düşünülürken [1], bu enflamatuar hastalık 20. yüzyılda diş yüzeyindeki lokal irritanlar ve biofilm ile ilişkili olarak ele alınmıştır; bu tanımın kullanımı günümüzde de hala devam etmektedir [2].

Günümüzde agresif periodontitis olarak bilinen periodontal hastalık ise 20. yüzyılın ikinci yarısına kadar net olarak tanımlanmamıştır. Son 30 yılda ise genç yaştaki hastalarda görülen şiddetli periodontal yıkım "generalize jüvenil", "hızlı ilerleyen" veya "şiddetli" periodontitis olarak adlandırılmıştır [3, 4]. Gottlieb, daha çok gençlerde görüldüğü ve yaygın bir enflamasyon belirtisi bulunmadığ için periodontal hastalığın bu tipinin enflamatuar özellikte olmadığını ileri sürmüş; başlangıcının biofilm veya diştaşı gibi lokal irritanlarla ilişkili olmadığını savunmuştur [5]. Bu hastalık için 1966'da yaygın, enflamatuar olmayan periodontal hastalık tanımının doğru olmadığına karar verilmiş [6]; 1989 ve 1993 yıllarındaki toplantılarda, genç bireyleri etkileyen farklı hastalıkların tamamını kapsayan early onset periodontitis teriminin kullanılmas1 kararlaştırılmıştır [7, 8]. Periodontitisin bu tipine ait özellikler her yaşta görülebileceği için 1999 yılında hastalı̆̆ın sınıflandırmasında yaş sınırlandırması kaldırılarak

Nimet Gül GÖRGÜLÜ, Hatice Selin YILDIRIM, Kübra KUNDAK, Leyla KURU

Marmara Üniversitesi Diş Hekimliği Fakültesi, Periodontoloji Anabilim Dall

Submitted / Gönderilme: 14.09.2018

Accepted / Kabul: 25.06.2019 "agresif periodontitis" terimi kullanılmaya başlanmıştır [9]. Agresif periodontitistin lokalize ve generalize olmak üzere iki alt tipi vardır. Lokalize agresif periodontitis, özellikle hastalığın başlangıcında, ince biofilm ile ilişkili olarak minimal klinik bulgu gösterir [10]. Lokalize ve generalize agresif periodontitisin ayrıldığı noktalardan biri etkilenmiş diş sayısıdır. Lokalize agresif periodontitisin etkilediği dişler genel olarak birinci molarlar ve kesici dişlerle sinırliyken generalize agresif periodontitiste birinci molar ve kesici dişler dışında en az 3 daimi diş daha etkilenmiştir. Hastalığın şiddeti, subgingival mikroflorası ve genetik risk faktörleri açısından da farklılık gösterirler [11].

Hem kronik periodontitis hem de agresif periodontitis diş yüzeyinde oluşan biofilmin neden olduğu kompleks enfeksiyonlardır [12]; hastalığa neden olan mikroorganizmalar normal oral mikrofloranın bir parçasıdır [11]; periodontal ataşman ve alveol kemiği kaybının nedeni, biofilme karşı gelişen immün yanıttır [13]; antienfektif tedavi ikisi için de etkilidir [14]; tedavi edilmezse dişlerin kaybıyla sonuçlanır; etkilenen bireylerde periodontitis gelişimine etkisi olan sistemik bir rahatsızlık yoktur [9].

\section{Farklılıklar}

Kronik periodontitis ile agresif periodontitis, hastalığın başlangıç yaşı, ilerleme hızı, enflamasyonun klinik belirtileri, yıkım şekli, mikrobiyolojik özellikler, histopatolojik özellikler, genetik ve çevresel faktörler, tedaviye verdikleri yanıt bakımından farklılıklar gösterir (Tablo 1) [15]. 
Tablo 1. Kronik ve agresif periodontitisin farklılıkları

\begin{tabular}{|l|l|l|}
\hline & Kronik Periodontitis & Agresif Periodontitis \\
\hline Başlangıç Yaşı & $\begin{array}{l}\text { Genellikle orta yaş ve } \\
\text { üzerinde }(>55 \text { yaş) } \\
\text { ancak her yaş grubunda } \\
\text { görülebilir. }\end{array}$ & $\begin{array}{l}\text { Genellikle genç } \\
\text { hastalarda (<35 } \\
\text { yaş) ancak her yaş } \\
\text { grubunda görülebilir. }\end{array}$ \\
\hline İlerleme Hızı & $\begin{array}{l}\text { Yavaş ancak dönemsel } \\
\text { olarak hızlı yıkım } \\
\text { görülebilir. }\end{array}$ & Hızlı \\
\hline Yıkım Şekli & Genellikle yatay & Genellikle dikey \\
\hline $\begin{array}{l}\text { Enflamasyonun } \\
\text { Klinik } \\
\text { Belirtileri }\end{array}$ & $\begin{array}{l}\text { Mevcut etiyolojik faktölerle } \\
\text { ilişkili }\end{array}$ & $\begin{array}{l}\text { Mevcut etiyolojik } \\
\text { faktörlerin miktarılala } \\
\text { orantısız yıkım } \\
\text { görülebilir. }\end{array}$ \\
\hline $\begin{array}{l}\text { Genetik ve } \\
\text { Çevresel } \\
\text { Faktörler }\end{array}$ & $\begin{array}{l}\text { Genetik ve çevresel } \\
\text { faktörlerden etkilenir. }\end{array}$ & $\begin{array}{l}\text { Genetik geçişten söz } \\
\text { edilebilir. Çevresel } \\
\text { faktörlerden de } \\
\text { etkilenir }\end{array}$ \\
\hline
\end{tabular}

\section{Başlangıç Yaşı}

Her ne kadar 1999 yılında yapılan sınıflama yaş kriterini ortadan kaldırıldıysa da [9], hastalığın tespit edilme yaşı kronik veya agresif periodontitis ayrımında günümüzde sıklıkla kullanılmaktadır. Ataşman kaybı ve alveol kemiği rezorpsiyonu görülen agresif periodontitisli hastalar, benzer hasar görülen kronik periodontitisli hastalardan daha gençtir. Ancak her ikisi için de belirli bir yaş aralığı olmadığından sadece yaş kriterine bağlı kalarak teşhis koymak yanlıştır [15].

\section{Ilerleme Hızı}

Kronik periodontitis genellikle yavaş ilerlerken, agresif periodontitis hızlı ilerler [10]. Periodontal hastalıkların ilerleme hızını etkileyen faktörler; ağız hijyeni etkinliği, diş hekimine gitme sıklığı, genetik faktörler, diabetes mellitus gibi bazı sistemik hastalıklar, sigara gibi konak cevabını değiştiren faktörler ve ilerleyen yaştır [16, 17]. Baer [10], agresif periodontitiste görülen ataşman kaybının kronik periodontitisten yaklaşı 3-4 katı daha fazla olduğunu öne sürmüştür. Kronik periodontitisin doğal ilerleme hızı 0.2 $\mathrm{mm} / \mathrm{y}$ ıldır [16]. Bir çalışmada periodontal yıkım, $0.46 \mathrm{~mm} / \mathrm{y} ı 1$ olarak tespit edilmiştir ve bu hastalar günümüzde kullanılan sinıflamaya göre "generalize agresif periodontitis" olarak adlandırılmaktadır [18]. Ancak lokalize agresif periodontitisli 40 , generalize agresif periodontitisli 48 bireyin dahil edildiğ $i$ bir çalışmada; hastalığın ilerleme hızı $0.06 \mathrm{~mm} / \mathrm{y} ı 1$ olarak saptanmıştır [19]. Bu çalışmada, verilerin tüm ağız ortalama değerlere göre verilmiş olması, lokalize agresif periodontitiste etkilenmemiş ve ataşman kaybı gözlenmeyen diş sayısı fazla olduğundan özellikle lokalize agresif periodontitis düşünüldüğünde yanıltıcı olabilmektedir. Gunsolley ve ark. [19], agresif periodontitisin lokalize tipinde periodontal ataşman ve diş kaybının daha stabil olduğu ancak generalize agresif periodontitisli hastalarda zaman içerisinde diş ve periodontal doku kayıplarının daha hızlı ilerlediği sonucuna varmışlardır. Yine aynı çalışmada, başlangıçta lokalize agresif periodontitis tanısı konan 2 hastanın, 3 yıl sonunda generalize agresif periodontitise geçiş yaptığı görülmüştür [19].

\section{Enflamasyonun Klinik Belirtileri}

Kronik periodontitisli bireylerde agresif periodontitisli bireylere kıyasla daha fazla dişeti enflamasyonu mevcuttur. Tam olarak aydınlatılamamış olmakla birlikte; bu farkın hastalığın başlangıcı ve dolayısıyla diş yüzeyinde biriken mikrobiyal yükün miktarı ile ilişki olduğu düşünülmektedir. Kronik periodontitis hastalarının kök yüzeylerinde genellikle kompleks ve kalın bir biofilm mevcutken [20], lokalize agresif periodontitis hastalarında gram-negatif kok ve filamentöz bakteriler ile diğer mikroorganizmalardan oluşan ince biofilm vardır; diştaşı ya çok azdır ya da yoktur (Resim 1 ve 2) [10, 20].

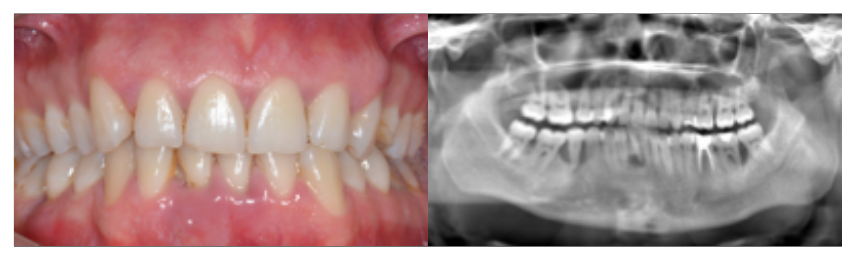

Resim 1. (a) Agresif periodontitisli 28 yaşındaki hastanın ağız içi klinik görüntüsü, (b) panoramik radrografi görüntüsü.

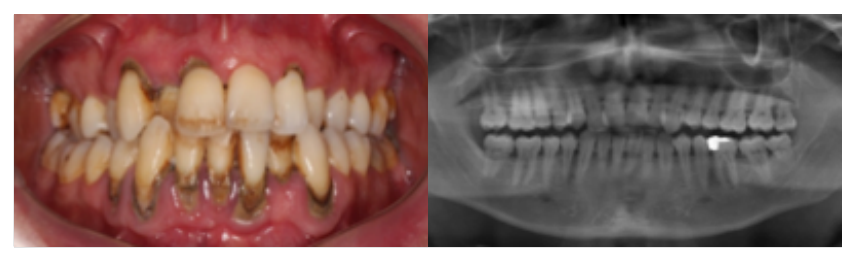

Resim 2. (a) Kronik periodontitisli 42 yaşındaki hastanın ağız içi klinik görüntüsü, (b) panoramik radrografi görüntüsü.

Lokalize agresif periodontitisde çok az dişeti enflamasyonu mevcuttur [10, 21, 22]. Ancak etkilenmiş bölgelerde sondalamada kanama, hafif kızarıklık ve dişeti kenarında ödem görülen lokalize agresif periodontitis hastaları da çoğunluğu oluşturmaktadır. Burmeister ve ark. [4], lokalize ve generalize agresif periodontitisli hastalarda ataşman kaybının görüldüğü bölgelerde, gingival indeks, 
dişeti kanaması ve süpürasyon skorlarının benzer derecede yüksek olduğunu görmüşlerdir. Hastalığın ileri evrelerinde, sondalama derinliği arttığında ve bu duruma periodontal desteğin azalması da eşlik ettiğinde, şiddetli klinik enflamasyondan söz edilebilir (Resim 3).

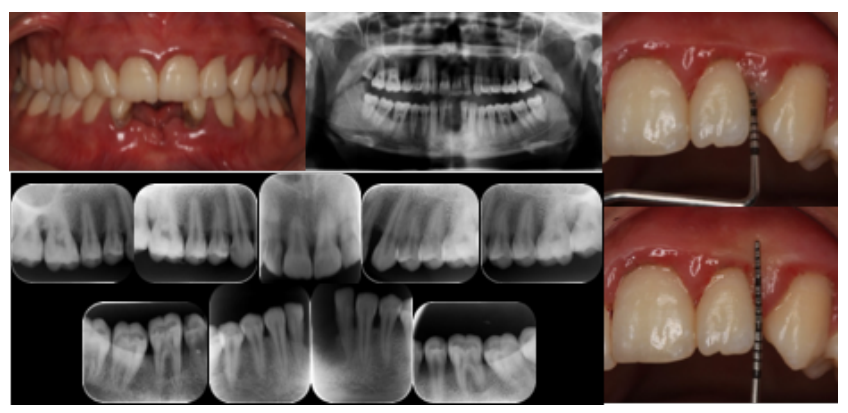

Resim 3. (a) Lokalize agresif periodontitisli 25 yaşındaki hastanın ağız içi klinik görüntüsü, (b) panoramik radyografi görüntüsü, (c) serigrafi görüntüsü, (d ve e) 22 nolu dişin distalindeki sondalama derinliği.

\section{Yıkım Şekli}

Kronik periodontitiste etkilenmiş belirli bir bölge veya belirli diş sayısı yoktur. Hastalık tek bir dişi veya tüm dentisyonu etkileyebilir; ancak bilateral simetrik yıkım göstermeye meyillidir [23]. Kronik periodontitiste, etkilenmiş bölge/diş miktarı $\leq \% 30$ ise hastalık lokalize, $>\% 30$ ise generalize olarak tanımlanır [9]. Agresif periodontitiste etkilenen dişler birinci molarlar ve kesici dişlerle sınırlı ise hastalık lokalize, birinci molar ve kesici dişler dişında en az 3 daimi diş daha etkilenmiş ise hastalık generalize olarak adlandırılır [9].

Radyografik değerlendirmede, kronik periodontitiste tipik bir kemik yıkım şeklinden söz edilemez. Yatay veya dikey yıkımlar görülebilir, yatay yıkımlar iatrojenik veya lokal faktörlerle ilişkili olabilir. Lokalize agresif periodontitiste kemik yıkımları, birinci molar ve kesici dişlerle sınırlıdır; özellikle molar dişlerin mesial yüzünde kemik kaybının görülmesi tipik bir radyografik görünümdür. Generalize agresif periodontitiste ise birinci molar ve kesici dişler haricinde en az 3 daimi diş daha etkilenmiştir ve dikey veya yatay kemik yıkımlarına rastlamak mümkündür. Kronik periodontitisin aksine, dişlerin çevresinde görülen kemik yıkımlarının şiddeti lokal faktörlerle orantılı değildir [24].

\section{Mikrobiyolojik Özellikler}

Kronikveagresifperiodontitislihastalardabulunansubgingival bakterilerin ancak \%50-60’1 günümüz teknolojisiyle laboratuvarda kültüre edilebilir; geri kalan mikroflora henüz kültüre edilememiştir $[25,26]$. Periodontitisin ilerlemesi episodiktir; farklı zamanlarda farklı bakterilerin yoğunluğu artar. $\mathrm{Bu}$ durum da patojen bakterilerin tespit edilmelerini güçleştirir [27]. Kronik ve generalize agresif periodontitisin subgingival mikrofloraları da farklılık göstermektedir (Tablo 2) [11]. Mombelli ve ark.'nın çalışmasında [28]; kronik ile agresif periodontitis hastaları arasinda Porphyromonas gingivalis, Aggregatibacter actinomycetemcomitans, Provetella intermedia, Tannerella forsythia ve Campylobacter rectus gibi periodontopatojenlerin varlığı ya da yokluğunun hastalıklarla ilişkisi bulunamamıştır. Agresif periodontitis tanısı konan hastalarda A. actinomycetemcomitans'ın pozitif olma sıklığının daha fazla olduğu sonucuna varılmıştır. Ancak A. actinomycetemcomitans' in negatif olduğu ve buna rağmen agresif periodontitis görülen hastaların da bulunduğu belirtilmiştir [28].

Tablo 2. Kronik ve agresif periodontitisin subgingival floralarındaki baskın periodontopatojenler

\begin{tabular}{l}
\multicolumn{2}{l}{$\begin{array}{l}\text { Kronik } \\
\text { Periodontitis }\end{array}$} & $\begin{array}{l}\text { Lokalize Agresif } \\
\text { Periodontitis }\end{array}$ & $\begin{array}{l}\text { Generalize } \\
\text { Agresif } \\
\text { Periodontitis }\end{array}$ \\
\hline
\end{tabular}

$P$. gingivalis'in her iki hastalıkla da yüksek oranda ilişkili olduğu görülmüştür[29]. Ancak bu mikroorganizma kronik periodontitisli bireylerin \%76.5'inden izole edilirken, generalize agresif periodontitisli bireylerin \%100'den izole edilmiştir [29]. Parvimonas micra da her iki hastalıkla ilişkilidir, çalı̧̧maya dahil edilen bireylerin üçte birinde bulunmuştur ve toplam izolasyonların \%4'ünü oluşturmaktadır [29]. Kronik periodontitis ile generalize agresif periodontitisin subgingival mikrofloraları arasındaki istatistiksel olarak anlaml fark $(\mathrm{p}=0.036)$ yalnızca $C$. rectus (kronik peridontitis \%23.5 ve agresif periodontitis \%50) için bulunmuştur [29]. Lafaurie ve ark. [30], her iki hastalığın subgingival mikroflorasinda $P$. gingivalis, T. forsythia, $C$. rectus, A. Actinomycetemcomitans ve enterik rodlar açısından belirgin bir farklılık bulamamışlardır. Ayrıca periodontal olarak sağl1klı hastalarda P. gingivalis (\%14.5), T. forsythia (\%3.1), C. rectus (\%22.7), A. actinomycetemcomitans (\%5) ve enterik rodlar (\%27) bulmuşlardır. Faveri ve ark. [31], 
generalize agresif periodontitis teşhisi konmuş 10 genç bireyde sondalama derinliği $\geq 7 \mathrm{~mm}$ olan bölgelerdeki subgingival mikroflorada yaklaşık 70 takson bulmuşlardır. Tüm hastalarda en çok rastlanılan iki tür Selenomonas ve Streptococcus'tur. Hastaların hiçbir bölgesinden elde edilen örneklerde kırmızı kompleks periodontopatojenlere rastlanmamışırı [31].

Lokalize agresif periodontitis nedeniyle çekilen dişlerin kök yüzeyleri elektron mikroskobu ile incelendiğinde, daha kalın ve yoğun birikintilerin görüldüğü kronik periodontitisin aksine, nispeten daha basit, ince, kalsifiye olmamış mikrobiyal birikintilere rastlanmıştır [20]. İmmunositokimyasal analiz sonucunda lokalize agresif periodontitiste görülen mikrobiyal yükte $A$. actinomycetemcomitans bulunduğu tespit edilmiştir [32]. $\mathrm{Bu}$ veriler lokalize agresif periodontitisin etyolojisinde $A$. actinomycetemcomitans'ın bazı türlerinin bulunduğunu destekleyen çalışmalar ile paralellik göstermektedir [33, 34]. $\mathrm{Bu}$ mikroorganizmaların bazı türlerinin hastalığın lokalize tipten generalize tipe geçişinde de etkili olduğu düşünülmektedir [35-37]. Birbirinden bağımsız iki çalışma, A. actinomycetemcomitans'in belirli türlerine sahip olan bireylerde lokalize agresif periodontitis gelişme riskinin, sahip olmayanlara kıyasla daha yüksek olduğunu göstermiştir $[36,37]$. Bu çalışmaların birinde periodontal olarak sağlıklı ve $A$. actinomycetemcomitans'in görüldüğü bireylerin, bu mikroorganizmanın görülmediği bireylerle karşılaştırılması sonucunda, A. actinomycetemcomitans'in pozitif olduğu bireylerin \%80'inde periodontitis gelişirken; negatif olduğu bireylerin yalnızca \%10'unda hastalık gözlenmiştir [36]. Diğer bir çalışmada başlangıçta periodontal olarak sağlıklı olan tüm bireylerin subgingival plak örneklerinde $A$. actinomycetemcomitans varlığına bakılmış; yüksek derecede lökotoksik olan JP2 klonu da özel olarak incelenmiştir. İki yılın sonunda, bireylerinde \%14.3'ünde, en az 1 bölgede, 3 mm veya daha fazla klinik ataşman kaybı görülmüştür. JP2 klonunun bulunduğu bireylerde klinik ataşman seviyesinde kayıp görülme oranı anlamlı olarak daha fazla bulunmuştur ( $<0.001)$. Başlangıçta A. actinomycetemcomitans'ın görüldüğü bireyler arasında hastalık gelişme riski en az olan grup JP2 klonu olmayan bireylerdir $(\mathrm{p}=0.012)$ [37]. Son olarak, lokalize agresif periodontitis, plağa bağlı görülen tüm periodontal hastalıklarda olduğu gibi, bir monoenfeksiyon değildir. Biofilmde bulunan diğer bakterilerin de en az $A$. actinomycetemcomitans kadar hastalığın etiyopatogenezinde rol oynadığı düşünülmektedir.

\section{Histopatolojik Özellikler}

Hem kronik hem de agresif periodontitiste, polimorfonüveli nötrofiller cep epitelinde bulunur ve epitelden dişeti cebine göç ederek bu bölgelerde biofilm ile dokular arasında bariyer oluşturur. Agresif periodontitisli kişilerin kök yüzeyleri yoğun bir şekilde nötrofillerle kaplıdır [38, 39]. Dişeti cebinde nötrofillerin salgıladığı lizozomal enzimler nedeniyle de hem kronik hem de agresif periodontitiste bağ dokusu yıkımı gözlenir.

\section{Genetik ve Çevresel Risk Faktörleri}

Agresif periodontitis için önemli bir risk faktörü olan genetik geçişin, bu hastalığın görüldüğü genç bireylerde etkili olduğuna dair güçlü kanıtlar mevcuttur. Ancak çoğu durumda hastanın yakınlarının muayenesi mümkün olmadığından hastalığa neden olan spesifik gen varyasyonu henüz çözülememiştir. Ayrıca kronik periodontitisin de genetik geçişli olabileceği savı nedeniyle sadece genetik geçişe bakarak hastalığın teşhisini koymak çok zordur. İki hastalığı da genetiğin etkilediğine dair kanıtlar vardır; ancak nasıl etkilediği anlaşılmamıştır [40].

Kronik ve agresif periodontitis hastaları arasında çevresel faktörlerin etkisi açısından genellikle fark yoktur. Sigara, her iki hastalığın da yaygınlığını artııı. Her ne kadar lokalize agresif periodontitisin yıkım şiddetinin plakla orantılı olmadığı söylense de ağız hijyeni hem agresif hem de kronik periodontitisin şiddetini doğrudan etkiler (Resim 4) [40].

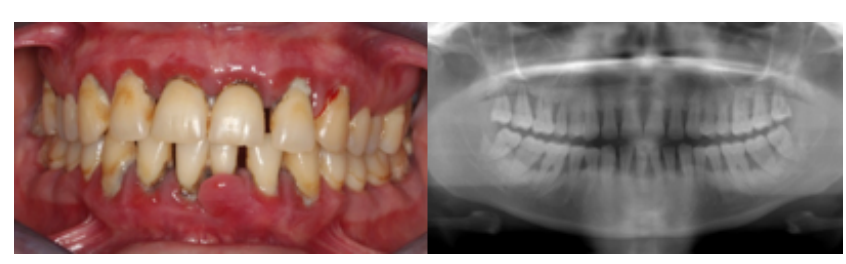

Resim 4. (a) Generalize agresif periodontitisli 34 yaşındaki hastanın ağız içi klinik görüntüsü, (b) panoramik radyografi görüntüsü.

\section{Tedavi Yanitı}

Kronik periodontitisli hastalara uygulanan başlangıç periodontal tedaviyle (BPT) başlangıç sondalama derinliği 4-6 $\mathrm{mm}$ olan bölgelerde sondalama derinliğinde $1 \mathrm{~mm}$ azalma ve $0.5 \mathrm{~mm}$ ataşman kazancı olduğu bildirilmiştir [41]. Sondalama derinliği $\geq 7 \mathrm{~mm}$ olan bölgelerde ise sondalama derinliğinde $2 \mathrm{~mm}$ azalma ve $1 \mathrm{~mm}$ ataşman kazancı sağlanmıştır [42]. BPT'ye ilave destekleyici antibiyotik 
kullanımının klinik etkisi az olmakla birlikte istatistiksel olarak anlamlı bulunmuştur [43]. Antibiyotik destekli BPT'de, yalnızca BPT'ye göre, sondalama derinliğinde 0.2$0.6 \mathrm{~mm}$ daha fazla azalma ve 0.1-0.2 mm daha fazla ataşman kazancı sağlanmıştır [44]. Kronik periodontitisli bireylerin tedavisinde, BPT ile birlikte cerrahi yöntemler uygulandığ 1 zaman, sondalama derinliğinde $0.6 \mathrm{~mm}$ ilave azalma ve $0.2 \mathrm{~mm}$ ilave ataşman kazancı olduğu bildirilmiştir [45]. Kronik periodontitiste görülen kemik yıkımları hem yatay hem de dikey olabildiği için BPT sonrasında bazen rezektif bazen de rejeneratif tedaviye başvurulabilir. Yönlendirilmiş doku rejenerasyonuyla tedavi edilen bireylerde, ataşman seviyesinde artış ve 2.7-2.1 mm kemik dolumu görülmüştür [46].

Diğer yandan agresif periodontitisin periodontal tedavilere verdiği yanıt net değildir. Kornman ve Robertson'un [47] yaptığı bir çalışmada lokalize agresif periodontitisli 8 hastaya uygulanan BPT'nin, sondalama derinliğine veya kültüre edilebilir siyah pigmentli bakterilerin oranına etkisinin olmadığı bildirilmiştir. Gunsolley ve ark. ise [19], BPT uyguladıkları bireylerde 15 yıl içerisinde periodontal ataşman kazancı olduğunu ve cerrahi olan veya olmayan tedaviler arasında tedaviye verilen yanıt açısından fark olmadığını öne sürmüşlerdir. Lokalize agresif periodontitisin ana etkenlerinden olan A. actinomycetemcomitans'in cep epiteline penetre olması nedeniyle antimikrobiyal ajan kullanımına ihtiyaç duyulmuştur [48]. Subgingival temizliği takiben 14 gün boyunca $1 \mathrm{~g}$ tetrasiklin $\mathrm{HCI}$ uygulamasının spiroket, $A$. actinomycetemcomitans ve Capnocytophaga türlerinin sayısını ciddi miktarda azalttığı ve $0.3 \mathrm{~mm}$ ataşman kazancı sağladığı bildirilmiştir [47]. Alternatif olarak metronidazol ve amoksisilinin kombine kullanımının sadece BPT’ye kıyasla sondalama derinliğinde daha fazla azalma, ataşman kazancında da daha fazla artışa ek olarak A. actinomycetemcomitans'in subgingival mikrofloradan eliminasyonunu sağladığı bildirilmiştir [43]. Lokalize agresif periodontitisinin cerrahi tedavisinde rejeneratif yöntemlerin yalnızca cerrahi olmayan kök yüzeyi temizliğine göre daha avantajlı olduğu görülmüştür. En iyi tedavinin rejeneratif tedaviye ilave olarak sistemik antibiyotik kullanımı olduğu görüşü öne sürülmüştür [14].

Generalize agresif periodontitis tedavisinde genellikle antibiyotik kullanımı tercih edilse de yalnızca BPT ile de sondalama derinliğinde azalma ve ataşman kazancı sağlandığı bildirilmiştir [49]. Subgingival klorheksidin irrigasyonunun tedavi parametrelerine etkisi olmadığ 1 öne sürülmüştür [50]. Ayrıca BPT’ye ek olarak uygulanan fotodinamik tedavinin A. Actinomycetemcomitans, $P$. gingivalis, T. forsythia,. P. intermedia Treponema. denticola üzerinde ilave bir etkisinin olmadığı gözlenmiştir [51]. BPT'ye ilave olarak sistemik antibiyotik kullanımın etkisi ile ilgili sonuçlar çelişkilidir. Tüm bu çalışmalardan yola çıkarak antibiyotik kullanımın tedaviye etkisinin çok az olduğu düşünülmektedir [50].

\section{SONUÇ}

Kronik periodontitis ve agresif periodontitisin benzer özelliklere sahip oldukları gibi, birbirlerinden ayrılmalarını sağlayan farklı noktaları da mevcuttur. Özellikle bu iki hastalığın klinik teşhisinde net bir ayrım ortaya koymak kolay olmayabilir. Periodontal hastalıkların yanı sıra periodontitise eşlik eden kötü ağız hijyeni, sigara kullanımı, diabetes mellitus gibi sistemik hastalıklar ve diğer çevresel faktörlerin varlığında doğru teşhis koymak zorlaşabilir. Bu nedenle hekimlerin bu iki hastalığın klinik, radyografik, mikrobiyolojik özelliklerine, ilerleme şekillerine/hızlarına ve mekanik tedaviye ek olarak yararlanılacak antienfektif tedavilere hâkim olması, bu hastalıkların doğru tanısı ve başarılı tedavisi açısından önem taşımaktadır. 